Article

\title{
Does Environmental Sustainability Impact Innovation, Ecological and Social Measures of Firm Performance of SMEs? Evidence from South Africa
}

\author{
Reginald Masocha ${ }^{D}$ \\ School of Economics and Management, University of Limpopo, Sovenga 0727, South Africa; \\ reemasocha@gmail.com; Tel.: +27-15-268-2802
}

Received: 17 September 2018; Accepted: 19 October 2018; Published: 24 October 2018

\begin{abstract}
This study investigated the question of whether environmental sustainability influences firm performance. Firm performance, a multidimensional construct, was researched utilizing innovation, ecological and social measures on the premises of SMEs in South Africa. Thus, the study hypothesized that environmental sustainability is positively and significantly related to innovation, ecological and social measures of firm performance. A cross-sectional research design was adopted in this study to test the abovementioned hypotheses. A total of 208 self-administered questionnaires distributed to SME owners and managers were analyzed utilizing structural equation modelling (SEM) and Amos Version 24 software. Primarily, the study established that environmental sustainability was significantly and positively correlated to all three measures of firm performance used in this study. Thus, the inferences from the findings suggest that environmental sustainability practices contribute positively towards firm innovation, ecological and social performances. The findings of this study greatly contribute towards the practice and theory of small businesses and firm performance by providing a more specific and streamlined perspective for approaching firm performance.
\end{abstract}

Keywords: environmental sustainability; innovation; ecological; social; firm performance; SMEs; South Africa

\section{Introduction}

The World Commission on Environment and Development (WCED) report notes that sustainable development requires firms to simultaneously develop long-term economic, social and environmental principles [1]. Thus, for firms to express sustainable development, they should incorporate these principles (economic prosperity, societal wellbeing and environmental promotion) in their products, policies and practices. The concept of sustainable development has become increasingly inescapable for the business world and continues to affect almost all aspects of business functions. The latest research shows evidence of sustainable development being utilised by business organisations as a competitive strategy [2,3]. Consequently, research demands and orientation are moving towards the delineation of the three dimensions of sustainable development with the intention of gaining precise and focused understanding of these premises within and across disciplines, business management included.

The concept of sustainable development has become something of a buzzword, however, its meaning has become somewhat confused and there is a great deal of misunderstanding around the term [4]. When the role of businesses is considered there are consistent incongruences associated with sustainable development. Inconclusive examinations on the contribution of the small business sector to the sustainability spectrum have been the subject of contentious research debate. As such, due to global output and employment concerns, it is ultimately and widely agreed that research on 
the economic contribution of SMEs could provide sustainable competitive advantage for all countries, especially in the developing world [5].

There is a general consensus amongst environmentalists and world leaders that if care is not taken, human life will cease to exist sooner than expected due to the increasingly destructive nature of human activities on "mother earth". Thus, the concept of environment and nature are frequently referred to when macro-environmental forces are considered in the current business environment. Rodríguez-Gutiérrez et al. [6] point out that research into SMEs has increased in the previous decade due to the significant contribution of this business sector to the ultimate performance of the economy. The traditional assertion that large firms are the major contributors to the economy is being challenged as the role of SMEs in the contemporary business environments is becoming better understood [7].

The need for SME businesses to proactively adopt sustainable management practices is supported as an ideal starting point in creating the change desired towards sustainable development [8]. The degree of proactivity in the adoption of sustainable development practices is said to depend on the size of the organisation, that is, large firms are deemed more likely than small firms to adopt [9]. There are advantages for small businesses in adopting sustainable development practices, which include benefits for society, increased stakeholder patronage, a competitive edge in the market, increased market share and boosts in shareholder value $[9,10]$. Consequently, researchers have assessed the individual dimensions of sustainable development such as environmental [11] and social $[12,13]$, as well as the integrated impact of all sustainable development dimensions on firm performance [14-17].

Despite numerous studies existing on the dimensions of sustainable development, their influence on firm performance is still not clear [18]. There is no consistent consensus with regards to the impact of sustainable development practices on the performance of small firms $[19,20]$. This study is a response to a major research gap in these studies, that is, the generalisation of the concept of firm performance. In the current discussion on sustainable development, the concept of firm performance needs to be streamlined to clearly articulate the outcomes of a firm's strategies, decisions and activities. Contemporary management theory and research need to distinguish between practices and outcomes that pertain to the sustainability discourse. In this case, this calls for a separation between sustainability practices and sustainability performance. Herein, this study utilises innovation, ecological and social dimensions as matrices of firm performance. The major objective that the study seeks to address pertains to the extent to which sustainable environmental development is a precursor to firm performance as measured by the innovation, ecological and social matrices of SMEs in Limpopo Province.

\section{Literature Review}

\subsection{Small Businesses and Environmental Sustainability}

The concept of environmental sustainability is the third aspect of the three major dimensions of the concept of sustainable development. In the literature, the framework of sustainable development is rooted in three pillars, namely, economic, social and environmental development, which form the basis for the overarching theory of this study [21]. The social dimension or social equity principle of sustainable development relates to all societal members having equal access to the available resources and opportunities. Critical to the definition of sustainable development is the realisation that "needs" present and future should be met in an equitable setting [22]. It has been stated that sustainability in meeting social needs implies a social equity between generations, and further considers equity within each generation. Ecological sustainability aims at firms reducing the size of their ecological footprint [23].

Environmental sustainability aims to sustain the natural support structures in an indefinite manner. The unchecked utilization of resources prevents the ability of life-support systems to function properly [21]. Every firm can have an impact on the environment, even by simply managing lighting 
of office buildings or more pronounced measures such as reducing production waste and emissions through three taxonomies, namely, pollution control, pollution prevention and product stewardship. It has been suggested that SMEs have a more significant bearing on the environment per unit than large firms. Even though previous research has focused on the impact of large firms on the environment, Musa and Chinniah [24] deemed that the integrated impact of SMEs on the environment is extensive. However, due to inadequate finances and lack of skilled labour, most SMEs were unable to assess their negative impact on the environment [25]. Furthermore, Musa and Chinniah [24] pointed out that many SMEs worldwide do not have adequate knowledge of environmental management and seldom understand the concept of environmental management. Consequently, the possibilities of SMEs being involved in activities that are environmentally friendly are very low.

The findings in the literature clearly suggest that the approaches of SMEs towards environmentalism substantially differ from those of large firms. For instance, evidence in the literature suggests that the ensuing negative and collective impact of SMEs towards environmental degradation may outweigh that of large corporations [24]. Additionally, Ghazilla et al. [26] indicate that many SMEs do not regard their activities as having significant environmental impact when compared with those of large corporations. For that reason, many SMEs do not consider lack of environmental management as a costly practice [27]. Consequently, the aggregation of SMEs' impact coupled with their no-effect mentality towards environmentalism points towards a devastating environmental impact by SMEs, individually and collectively.

Some writers argue that SMEs result in social stability because they cause in less damage to the physical environment when compared to large enterprises [28]. However, there are still high prospects of SMEs being either environmentally irresponsible or increasing their environmental damage under the pretext of "it is of no materiality". Furthermore, due to their lack of capacity in terms of skills, awareness, knowledge and financial capacity, SMEs are bound to be constrained in dealing with the environment when compared to large corporations. Previous studies found a significant positive relationship between the adoption and practice of sustainable development and firm performance amongst SMEs [29,30]. Wang and Sarkis [31] allude to a negative relationship between sustainability and firm performance. Other studies have also found a partially positive relationship between sustainable development and firm performance [32,33]. In this scenario, the studies established that the relationship varied with the type of firm performance measures that were utilised.

\subsection{Firm Performance}

Multidimensionality implies that each dimension represents a single element of the ultimate results of the firm, which are represented by a certain set of indicators. Commonly, a multidimensional model implies that firm performance would be represented by two second-order dimensions namely, financial and non-financial performance [34]. An exhaustive exploration of multidimensional constructs should examine second-order dimensions that can characterize first-order dimensions. These observed indicators should cluster collectively under one dimension, with higher correlations within the group than with other indicators from separate dimensions [35]. Theoretically as well as empirically, the literature strongly suggests the concept of multidimensionality and utilising several of the dimensions that underlie the intricate and entire concept of firm performance [34].

To date, most of the studies on firm performance have concentrated on the aspect of financial performance and excluded other metrics of firm performance. For sustainability studies, the financial performance variable has been examined against environmental sustainability. However, the relationships between environmental sustainability and innovation, ecological and social variables of firm performance constructs have not been fully researched. More and more firms, SMEs included, are recognising the benefits that emanate from pursuing sustainable innovation, ecological goals and measure their performance on these indicators. Accordingly, eco-innovativeness reduces costs (e.g., an energy management system), minimises risks (e.g., through enhanced safety features), enhances sales and profitability (e.g., through the use of premium organic brands), improves reputation and 
brand value, enhances attractiveness as an employer and builds up innovation capabilities [36]. Bossle et al. [37] also propose that eco-innovativeness enhances performance and competitiveness. Thus, given this background the following hypothesis was proposed to specify and streamline the concept of firm performance:

Hypothesis 1 (H1). There is a significant positive relationship between environmental sustainability practices and innovation in firm performance of SMEs in Limpopo Province.

Environmental performance is significantly determined by the utilisation of proficient and cleaner sustainable resources in producing energy. Herein, it is essential to ensure that there are low levels of carbon dioxide emissions during the operational process [26]. Contemporary literature frequently attests to the existence of a positive relationship between financial performance and environmental performance as well as overall firm performance. For instance, environmental performance is deemed to be positively and significantly correlated to the firm's market value, market performance and financial performance [38]. Therefore, this justifies the need to focus on environmental performance as a measure of firm performance within the sustainable development discourse for SMEs. Given that background, the following hypothesis was postulated:

Hypothesis 2 (H2). There is a significant positive relationship between environmental sustainability practices and environmental performance of SMEs in Limpopo Province.

Social performance pertains to the firm's actual accomplishments in enhancing and sustaining the standards of living without disregarding environmental issues. Social performance focuses on ensuring that firms simultaneously achieve profits and societal well-being. Thus, profits should not be achieved at the expense of social degradation [39]. The traditional measure of firm performance, that is primarily through financial performance, has recently been questioned due to its limitations in ascertaining issues like social performance [40]. Social performance measures are deemed to reveal the overall firm performance in environmental management, strategic governance, labour relations and stakeholder management [7]. In a Polish study, Urbaniec [41] notes that the indicators of social performance pertain to those that improve the quality of life of society. However, the measurement of social performance has been questioned and dismissed, with most firms relying on assessing financial performance. This is a result of the challenges that are associated with measuring the social outcomes of a firm's activities. Unfortunately, firms that do so are susceptible to being derailed by firms that seldom pay attention social issues [42]. Thus, the following hypothesis is proposed:

Hypothesis $\mathbf{3}$ (H3). There is a significant positive relationship between environmental sustainability practices and social performance of SMEs in Limpopo Province.

\section{Research Methodology}

The study utilised a positivism research paradigm and followed a quantitative research methodology approach as it focused on numerical data to attain the research conclusions. The study gathered data utilising SME owners and managers as respondents in the study. A self-administered questionnaire was employed to gather data. The study was conducted in the Limpopo province of South Africa. The convenience sampling technique was employed in this study because most SMEs fall under the informal sector, thus making it difficult to establish a sample frame for the purposes of utilising probability sampling techniques. A total of 208 questionnaires were used in the final sample, which represents an effective response rate of $52 \%$ out of the 400 that were initially distributed. The questionnaires were distributed personally as well as electronically during the month of September 2017. The questionnaire employed in this study was composed of items that were adopted from existing literature and comprised of 5-point Likert scale type of questions from "strongly agree" to "strongly disagree".

The gathered data was analysed for descriptive and inferential statistics through version 24 of the IBM SPSS and IBM AMOS software packages, respectively. The structural equation modelling (SEM) 
approach was used as the main inferential statistical analysis to obtain the research conclusions in the study. The SEM process followed the prominent two-staged approach, namely, the measurement model and structural model. The preliminary, prerequisite analysis for SEM, namely, exploratory factor analysis (EFA), confirmatory factor analysis (CFA) as well as tests for outliers, normality, reliability and validity were also conducted.

\section{Results}

\subsection{Sample Characteristics}

For the purposes of the SEM approach, a minimum sample size of 200 has been recommended and the study meets that prescription. The sample in the study constituted managers $(63.5 \%)$ and owners $(36.5 \%)$ who were conversant with the decisions and practices of firms, which were required for the study. The majority of the respondents were females (51.9\%), aged between $41-50$ years $(40.4 \%)$, educated with a matric certificate $(37 \%)$, had been in business for a period of one to five years $(44.2 \%)$ and employed between $6-20$ workers (43.3\%). Table 1 below diagrammatically summarises the information pertaining to the demographic characteristics of the sample participants as well as the firm attributes.

Table 1. Sample characteristics.

\begin{tabular}{|c|c|c|c|}
\hline Variables & Category & Frequency & Frequency $(\%)$ \\
\hline \multirow[t]{2}{*}{ Position in business } & Owner & 76 & 36.5 \\
\hline & Manager & 132 & 63.5 \\
\hline \multirow[t]{2}{*}{ Gender } & Male & 100 & 48.1 \\
\hline & Female & 108 & 51.9 \\
\hline \multirow[t]{5}{*}{ Age (Years) } & Below 21 & 2 & 1.0 \\
\hline & $21-30$ & 68 & 32.7 \\
\hline & $31-40$ & 84 & 40.4 \\
\hline & $41-50$ & 43 & 20.7 \\
\hline & Above 50 & 11 & 5.3 \\
\hline \multirow[t]{5}{*}{ Education } & Informal & 7 & 3.4 \\
\hline & Below Matric & 26 & 12.5 \\
\hline & Matric & 77 & 37.0 \\
\hline & Diploma/Cert & 70 & 33.7 \\
\hline & Degree & 28 & 13.5 \\
\hline \multirow[t]{4}{*}{ Duration } & Below 1 & 17 & 8.2 \\
\hline & $1-5$ & 92 & 44.2 \\
\hline & $6-10$ & 67 & 32.2 \\
\hline & Above 10 & 32 & 15.4 \\
\hline \multirow[t]{4}{*}{ No. of workers } & 5 and less & 75 & 36.1 \\
\hline & $6-20$ & 90 & 43.3 \\
\hline & $21-50$ & 37 & 17.8 \\
\hline & $51-200$ & 6 & 2.9 \\
\hline
\end{tabular}

\subsection{Measurement Model}

Prior to performing the measurement model, EFA assessment was conducted and the prerequisites for EFA were satisfied. Thus, the Kaiser-Meyer-Olkin (KMO) measure of sampling adequacy was 0.896 and Bartlett's Test of Sphericity was significant $(p<0.000)$. The KMO index is particularly recommended when the cases to variable ratio are less than 1:5. The KMO index ranges from 0 to 1 , with items with KMO values above 0.5 considered suitable for factor analysis. The Bartlett's Test of Sphericity should be significant $(p<0.05)$ to be suitable for factor analysis $[43,44]$. The measurement model pertains to the relationship between the latent variables and the observable items per each 
construct. The model constituted CFA as well as internal consistency measured through construct validity assessments.

Two forms of construct validity were performed, namely, convergent and divergent validity. Convergent validity as ascertained through item standardised factor loadings (SFLs), composite reliability (CR) and average variance extracted (AVE) are shown in Table 2. According to Table 2, SFLs exceeded the prescribed minimum threshol of 0.60 for all the questionnaire items [45], as such all items are included in further assessments. Furthermore, Table 2 indicates that all the $C R$ values were above 0.70 and the AVE values exceeded the recommended 0.50 which portrays significant internal consistency [44]. Finally, discriminant validity is indicated in Table 3, whereby using Fornell-Lacker criterion, all the square root of the AVE of each variable exceeded their respective correlation.

Table 2. Convergent validity of items in the measurement model.

\begin{tabular}{ccccc}
\hline Construct & Item & Item Loading & CR & AVE \\
\hline & ESD1 & 0.843 & 0.947 & 0.692 \\
Environmental Sustainable development (ESD) & ESD2 & 0.873 & & \\
& ESD3 & 0.853 & & \\
& ESD4 & 0.883 & & \\
& ESD6 & 0.893 & & \\
& ESD7 & 0.822 & & \\
& ESD8 & 0.744 & & \\
Innovation Firm Performance (IFP) & IP1 & 0.910 & 0.925 \\
& IP2 & 0.925 & & \\
& IP3 & 0.766 & & \\
& IP4 & 0.858 & & \\
Ecological Firm Performance (EFP) & EP1 & 0.742 & 0.946 \\
& EP2 & 0.972 & & \\
& EP3 & 0.982 & & \\
& EP4 & 0.895 & 0.922 & 0.748 \\
\hline
\end{tabular}

Table 3. Discriminant validity (Fornell-Larcker criterion).

\begin{tabular}{ccccc}
\hline Construct & ESD & IFP & EFP & SFP \\
\hline ESD & $\mathbf{0 . 8 3 2}$ & & & \\
IFP & 0.549 & $\mathbf{0 . 8 6 9}$ & & \\
EFP & 0.624 & 0.597 & $\mathbf{0 . 9 0 4}$ & \\
SFP & 0.440 & 0.468 & 0.413 & $\mathbf{0 . 8 6 5}$ \\
\hline
\end{tabular}

$\mathrm{SD}$, standard deviation. The square root of AVE (Average Variance Extracted) values are presented diagonally (in bold).

\subsection{Structural Model}

The structural model aims to reflect the causal relationships pertaining to the latent variables in the research model. The structural model is comprised of the estimation of path regression weights or path coefficients $(\beta)$ as well as the R-squared $\left(R^{2}\right)$ values. The $R^{2}$ statistic in SEM serves to indicate the prediction ability of the research [45]. The $\mathrm{R}^{2}$ values obtained in the model indicated that the model explains $32 \%, 40 \%$ and $21 \%$ of variance in IFP, EFP and SFP as dependent variables. The model fitness was within the acceptable ranges, namely, the Normed Chi-Square $\left(\mathrm{X}^{2} / \mathrm{df}=2.92\right)$, Tucker Lewis Index $(\mathrm{TLI}=0.912)$, Comparative Fit Index $(\mathrm{CFI}=0.948)$ as well as Root Mean Square Error of Approximation $($ RMSEA $=0.069)$. Furthermore, AMOS version 24 software enabled the combination of the CFA and 
structural model, with the CFA outlining the indicators for each latent variable measured. Figure 1 is the diagrammatic representation of the results of the structural model together with the CFA.

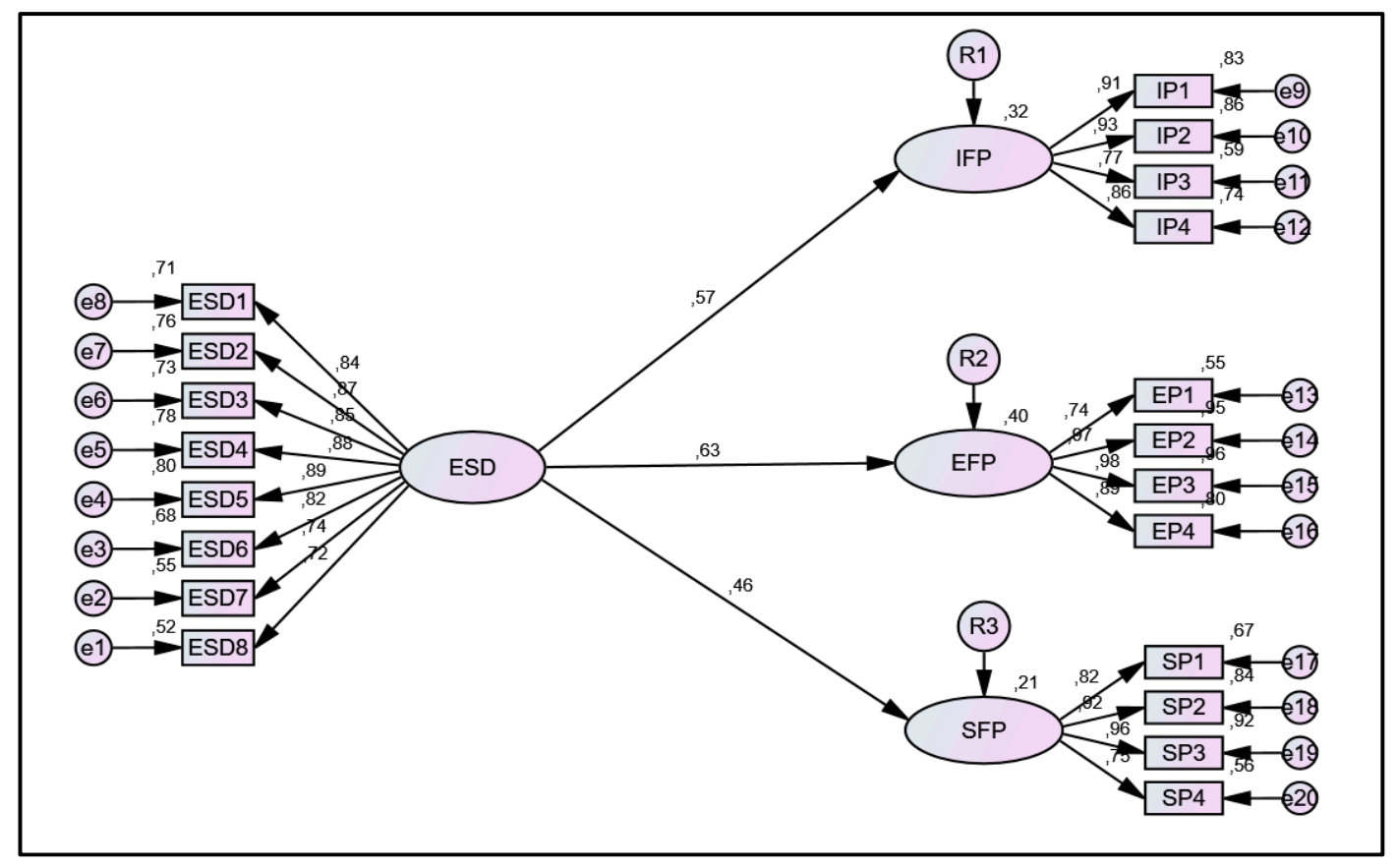

Figure 1. Structural model with path coefficients.

As shown in Figure 1, the structural model results indicate that $\mathrm{H} 1(\beta=0.566 ; p<0.000)$, $\mathrm{H} 2(\beta=0.633 ; p<0.000)$, as well as H3 $(\beta=0.455 ; p<0.000)$ were all positive and significant. Thus, all the null hypotheses in this study were rejected resulting in support for all the alternative hypotheses. These results are further illustrated in Table 4.

Table 4. Results of hypotheses testing.

\begin{tabular}{|c|c|c|c|c|c|c|c|}
\hline \multicolumn{3}{|c|}{ Hypothesised Relationships } & \multirow{2}{*}{$\frac{\beta}{0.566}$} & \multirow{2}{*}{$\begin{array}{c}\text { S.E. } \\
0.076\end{array}$} & \multirow{2}{*}{$\begin{array}{c}\text { C.R. } \\
7.863\end{array}$} & \multirow{2}{*}{$\begin{array}{c}p \\
* * *\end{array}$} & \multirow{2}{*}{$\begin{array}{c}\text { Decision } \\
\text { Supported }\end{array}$} \\
\hline ESD & $\rightarrow$ & IFP & & & & & \\
\hline ESD & $\rightarrow$ & EFP & 0.633 & 0.068 & 8.058 & $* * *$ & Supported \\
\hline ESD & $\rightarrow$ & SFP & 0.455 & 0.078 & 6.215 & $* * *$ & Supported \\
\hline
\end{tabular}

$\beta$, standardised regression weight; S.E., standard error; C.R., critical ratio; $p$, probability value; ${ }^{* * *}$, Denotes $p<0.001$.

\section{Discussion}

According to Tachizawa et al. [46], there is plenty of literature on the impact of environmental practices on firm performance. However, the relationship between supplier-related environmental practices and firm performance is a contentious subject and in-depth analysis is required considering the various dimensions of the concept. According to the stated hypotheses, sustainable environmental development was found to be a precursor to the firm performance of SMEs as measured by the matrices utilised in this study. Thus, the three hypotheses pertain to the relationship between environmental sustainability development and innovation performance, environmental performance, as well as social performance. The SEM analytical approach resulted in all these propositions being consistent with the assumptions that were outlined earlier in the research. Thus, the research established that the more sustainable environmental development a firm gets involved in, the more innovation performance is experienced as well as environmental and social performance.

Innovation, environmental and social aspects as measures of firm performance are herein purported to be influenced by environmental sustainability. Thus, the key finding alludes 
to the fact that environmental concerns and aspirations have a bearing on the innovation, social and environmental outcomes of firms. The results established through SEM analysis, substantiated findings from earlier studies concerning the impact of environmental sustainability and firm performance [30,47]. Specifically, Theyel and Hofmann's [48] findings pertaining to a positive relationship between environmental sustainability and innovation performance were supported. This means that SME owners/managers perceive that the more their firms participate in environmentally sustainable practices, the more innovation, environmental and social performance is recorded. The research findings advance and substantiate the need for an extensive and comprehensive approach to the concept of firm performance within the discourse of sustainable development. The traditional approach to firm performance assessment is deemed to be inconsistent and insufficient to answer the sustainable development challenges faced by the world. Various performance matrices and measures have been outlined in the sustainability literature. However, innovation, social and environmental measures have hardly been addressed. These findings are critical for the management practises and strategies of SMEs. Direct insights that can be deduced from the findings are that when SMEs find themselves falling short in terms of innovation, social and environmental outcomes, environmental sustainability can be utilised as the tool for stimulation. Implicitly, small businesses' involvement in environmentally sustainable development practices is expected to significantly contribute towards their overall business performance. Furthermore, the study indicates that environmentalism is increasingly becoming a macro-environmental variable with unsparing effects on businesses.

\section{Conclusions}

This study researched the relationship between environmental sustainability and the three indicators of firm performance that have been recently discussed in literature, namely, innovation, environmental and social. Overall, this study established the positive consequences of adopting sustainable development practices towards the three researched aspects of firm performance and suggests that SMEs that disregard the adoption of environmentally sustainable development risk failure in the current environment. The findings have further implications for policy formulation and government decisions. The business case for environmentally sustainable practices suggest that government decisions could consider the formulation of policies that stimulate the adoption and participation of SMEs in environmentally sustainable development. This will improve the long-term sustainability or survival of SMEs as one of the challenges for SMEs has been disregarding the environment. Furthermore, the findings have positive implications for governments, which have long desired and strived for environmental protection measures. For government to enhance sustainability, the role played by SMEs is a worthwhile consideration. Thus, government can achieve greater environmental protection if they can implement policies and strategies that encourage environmental protection. Such programs could come in the form of subsidies and support that is directed towards small businesses that participate in environmental sustainability.

Although the results and recommendations established in this study have far-reaching effects, these need to be interpreted with cognisance of the limitations that are inherent in this study. Firstly, the study was approached primarily through non-probability sampling. As such, the representativeness of the sample is compromised. Thus, the results need to be replicated in other areas to substantiate the model presented in this study. Also, the sample utilised in this study was from one province of South Africa, meaning that the results cannot be generalised to the rest of South Africa. Consequently, future studies in other parts of the country as well as of a broader spectrum, need to be conducted as they posit a research gap. Particularly, future research studies need to be conducted in the wider African context to ascertain the model postulated in this study.

Funding: The APC was funded by the University of Limpopo.

Conflicts of Interest: The author declares no conflict of interest. 


\section{References}

1. Galpin, T.; Whittington, J.L.; Bell, G. Is your sustainability strategy sustainable? Creating a culture of sustainability. Corp. Gov. 2015, 15, 1-17. [CrossRef]

2. Thiel, M. Unlocking the social domain in sustainable development. World J. Sci. Technol. Sustain. Dev. 2015, 12, 183-193. [CrossRef]

3. Masocha, R. Sustainable Marketing Practices and Sustainable Consumer Behaviour of Tertiary Students in South Africa. J. Econ. Behav. Stud. 2018, 10, 248-257. [CrossRef]

4. Ratiu, C.; Anderson, B.B. The identity crisis of sustainable development. World J. Sci. Technol. Sustain. Dev. 2014, 11, 4-15. [CrossRef]

5. Williams, B.R.; O'Donovan, G. The accountants' perspective on sustainable business practices in SMEs. Soc. Responsib. J. 2015, 11, 641-656. [CrossRef]

6. Rodríguez-Gutiérrez, M.J.; Moreno, P.; Tejada, P. Entrepreneurial orientation and performance of SMEs in the services industry. J. Organ. Chang. Manag. 2015, 28, 194-212. [CrossRef]

7. Wang, Y. What are the biggest obstacles to growth of SMEs in developing countries? An empirical evidence from an enterprise survey. Borsa Istanbul Rev. 2016, 1-10. [CrossRef]

8. Urban, B.; Naidoo, R. Business sustainability: Empirical evidence on operational skills in SMEs in South Africa. J. Small Bus. Enterp. Dev. 2012, 19, 146-163. [CrossRef]

9. Gomes, C.M.; Kneipp, J.M.; Kruglianskas, I.; da Rosa, L.A.B.; Bichueti, R.S. Management for sustainability: An analysis of the key practices according to the business size. Ecol. Indic. 2015, 52, 116-127. [CrossRef]

10. Høgevold, N.M.; Svensson, G.; Klopper, H.B.; Wagner, B.; Valera, J.C.S.; Padin, C.; Ferro, C.; Petzer, D. A triple bottom line construct and reasons for implementing sustainable business practices in companies and their business networks. Corp. Gov. 2015, 15, 427-443. [CrossRef]

11. González-Benito, J.; González-Benito, Ó. Environmental proactivity and business performance: An empirical analysis. Omega Elsevier 2005, 33, 1-15. [CrossRef]

12. Lankoski, L. Cost and revenue impacts of corporate responsibility: Comparisons across sustainability dimensions and product chain stages. Scand. J. Manag. 2009, 25, 57-67. [CrossRef]

13. Hull, C.E.; Rothenberg, S. Firm performance: The interactions of corporate social performance with innovation and industry differentiation. Strateg. Manag. J. 2008, 29, 781-789. [CrossRef]

14. Wagner, M. The role of corporate sustainability performance for economic performance: A firm-level analysis of moderation effects. Ecol. Econ. 2010, 69, 1553-1560. [CrossRef]

15. Lopez, M.V.; Garcia, A.; Rodriguez, L. Sustainable development and corporate performance: A study based on the Dow Jones Sustainability Index. J. Bus. Ethics 2007, 75, 285-300. [CrossRef]

16. Chang, D.; Kuo, L.R. The effects of sustainable development on firms' financial performance-An empirical approach. Sustain. Dev. 2008, 16, 365-380. [CrossRef]

17. Goyal, P.; Rahman, Z.; Kazmi, A.A. Corporate sustainability performance and firm performance research. Manag. Decis. 2013, 51, 361-379. [CrossRef]

18. Moneva, E.O.J.M.; Álvarez, I. Sustainable supply chain and company performance. Supply Chain Manag. Int. J. 2014, 19, 332-350.

19. Adebanjo, D.; Teh, P.; Ahmed, P.K. The impact of external pressure and sustainable management practices on manufacturing performance and environmental outcomes. Int. J. Oper. Prod. Manag. 2016, 36, 995-1013. [CrossRef]

20. Curkovic, S.; Sroufe, R.A. Literature Review and Taxonomy of Environmentally Responsible Manufacturing. Am. J. Ind. Bus. Manag. 2016, 6, 323-346. [CrossRef]

21. Goodland, R. The concept of environmental sustainability. Annu. Rev. Ecol. Syst. 1995, 26, 1-24. [CrossRef]

22. Swanson, L.A.; Zhang, D.D. Perspectives on corporate responsibility and sustainable development. Manag. Environ. Qual. Int. J. 2012, 23, 30-639. [CrossRef]

23. Borim-de-Souza, R.; Balbinot, Z.; Travis, E.F.; Munck, L.; Takahashi, A.R.W. Sustainable development and sustainability as study objects for comparative management theory. Cross Cult. Manag. 2015, 22, 201-235. [CrossRef]

24. Musa, H.; Chinniah, M. Malaysian SMEs Development: Future and Challenges on Going Green. Procedia Soc. Behav. Sci. 2016, 224, 254-262. [CrossRef] 
25. Stubblefield Loucks, E.; Martens, M.L.; Cho, C.H. Engaging small- and medium-sized businesses in sustainability. Sustain. Account. Manag. Policy J. 2010, 178-200. [CrossRef]

26. Ghazilla, R.A.R.; Sakundarini, N.; Abdul-Rashid, S.H.; Ayub, N.S.; Olugu, E.U.; Musa, S.N. Drivers and barriers analysis for green manufacturing practices in Malaysian SMEs: A Preliminary Findings. Procedia CIRP 2015, 26, 658-663. [CrossRef]

27. Masocha, R.; Fatoki, O. The impact of coercive pressures on sustainability practices of small businesses in South Africa. Sustainability 2018, 10, 32. [CrossRef]

28. Zindiye, S. An Empirical Investigation into the Factors Affecting the Performance of Small and Medium Enterprises in the Manufacturing Industry of Harare, Zimbabwe. Master's Thesis, University of Fort Hare, Alice, South Africa, 2008.

29. Clemens, B. Economic incentives and small firms: Does it pay to be green? J. Bus. Res. 2006, 59, 492-500. [CrossRef]

30. Russo, A.; Tencati, A. Formal vs. informal CSR strategies: Evidence from Italian micro, small, medium-sized, and large firms. J. Bus. Ethics 2009, 85, 339-353. [CrossRef]

31. Wang, Z.; Sarkis, J. Investigating the relationship of sustainable supply chain management with corporate financial performance. Int. J. Prod. Perform. Manag. 2013, 62, 871-888. [CrossRef]

32. Azevedo, S.G.; Carvalho, H.; Machado, V.C. The influence of green practices on supply chain performance: A case study approach. Transp. Res. Part E 2011, 47, 850-871. [CrossRef]

33. Wu, Z.; Pagell, M. Balancing priorities: Decision-making in sustainable supply chain management. J. Oper. Manag. 2011, 29, 577-590. [CrossRef]

34. Santos, J.B.; Brito, L.A.L. Toward a Subjective Measurement Model for Firm Performance. Braz. Acad. Rev. 2012, 9, 95-117. [CrossRef]

35. Sambharya, R.B. Security analysts' earnings forecasts as a measure of firm performance: An empirical exploration of its domain. Manag. Decis. 2011, 49, 1160-1181. [CrossRef]

36. Klewitz, J.; Zeyen, A.; Hansen, E.G. Intermediaries driving eco-innovation in SMEs: A qualitative investigation. Eur. J. Innov. Manag. 2012, 15, 442-467. [CrossRef]

37. Bossle, M.B.; De Barcellos, M.D.; Vieira, L.M. Why food companies go green? The determinant factors to adopt eco-innovations. Br. Food J. 2016, 118, 1317-1333. [CrossRef]

38. Halati, A.; He, Y. Intersection of economic and environmental goals of sustainable initiatives. J. Clean. Prod. 2018, 189, 813-829. [CrossRef]

39. Abdul-Rashid, S.H.; Sakundarini, N.; Ghazilla, R.A.R.; Ramayah, T. The impact of sustainable manufacturing practices on sustainability performance Empirical evidence from Malaysia. Int. J. Oper. Prod. Manag. 2017, 37, 182-204. [CrossRef]

40. Ilhan-Nas, T.; Koparan, E.; Okan, T. The effects of the CSR isomorphism on both CSP and CFP. J. Asia Bus. Stud. 2015, 9, 251-272. [CrossRef]

41. Urbaniec, M. Sustainable Development Indicators in Poland: Measurement and System Evaluation. Entrep. Bus. Econ. Rev. 2015, 3, 119-134. [CrossRef]

42. Siti-Nabiha, A.K.; Azhar, Z.; Isa, S.M.; Siti-Nazariah, A.Z. Measuring social performance: Reconciling the tension between commercial and social logics. Int. J. Soc. Econ. 2018, 45, 205-222. [CrossRef]

43. Tabachnick, B.; Fidell, L. Using Multivariate Statistics, 5th ed.; Pearson Education: Needham Heights, MA, USA, 2007.

44. Williams, B.; Brown, T.; Onsman, A. Exploratory factor analysis: A five-step guide for novices. Aust. J. Paramed. 2010, 8, 1-13.

45. Hair, J.; Hult, T.; Ringle, C.; Sarstedt, M. A Primer on Partial Least Squares Structural Equation Modeling (PLS-SEM); Sage Publications, Inc.: Thousand Oaks, CA, USA, 2014.

46. Tachizawa, E.M.; Gimenez, C.; Sierra, V. Green supply chain management approaches: Drivers and performance implications. Int. J. Oper. Prod. Manag. 2015, 35, 1546-1566. [CrossRef] 
47. Groenewald, D.; Powell, J. Relationship between sustainable development initiatives and improved company financial performance: A South African perspective. Acta Commer. 2016, 16, 1-14. [CrossRef]

48. Theyel, G.; Hofmann, K. Stakeholder relations and sustainability practices of US small and medium-sized manufacturers. Manag. Res. Rev. 2012, 35, 1110-1133. [CrossRef] 